\title{
STUDIES IN THE SCRIBAL HABITS OF CODEX SINAITICUS ${ }^{1}$
}

\section{Dirk Jongkind}

Those who have visited the British Library and its magnificent treasure gallery will undoubtedly have taken a look at one of the most famous Biblical codices, the Codex Sinaiticus. Written in the fourth century on large parchment sheets, it must have contained in a single volume both the Greek Old and New Testament. The New Testament part of the manuscript is complete, whilst a large part of the Old Testament is missing. Constantin Tischendorf brought the first part of the manuscript from St. Catherine's monastery to Leipzig in 1846, and these 43 leaves of the Old Testament - still in the University Library of Leipzig - were originally published under the name Codex FridericoAugustanus. In 1859, returning from his third visit to Mt. Sinai, Tischendorf carried the bulk of the manuscript with him to St. Petersburg and published its contents in 1862. The cash-stripped Russian government sold the manuscript to the British Museum in 1934, and since 1999 the manuscript has been at its present location. After the acquisition it was decided to make a thorough study of the manuscript, and this study resulted in the 1938 monograph Scribes and Correctors of the Codex Sinaiticus by H. J. M. Milne and T. C. Skeat. The two authors demonstrated that the whole manuscript was copied by three different scribes, who were also responsible for the earliest corrections to the text, the running titles, and other supplementary material. Besides the general appearance of the script, Milne and Skeat used two further arguments for the identification of the three hands: a) the shape of the coronis at the end of each book - each scribe displays a distinct pattern, and b) the characteristic spelling that each scribe uses. The letter pairs $\alpha 1-\varepsilon$ and $\varepsilon 1-1$ were freely interchanged and it is possible to recognise a scribe solely on the basis of the pattern and frequency of these changes. On the basis of this fluidity in spelling,

1 Abstract of a Ph.D. thesis, University of Cambridge, 2005. Supervisor: Dr. Peter M. Head. 
Milne and Skeat argued that it was most likely that Sinaiticus was written by dictation: one person reads out the text, which is simultaneously written down by a number of scribes, thus creating several copies at the same time. My thesis considers a couple of phenomena which argue against such dictation. At several places, for example, a deliberate attempt is made to squeeze the text of Sinaiticus in, so as to ensure that a book would not flow over onto the next gathering of leaves. Apparently, the scribes made calculations as to how much text they needed for a particular work and adjusted the density of the text accordingly. Such activity is difficult to imagine in a setting in which a text is dictated.

Starting at the point where Milne and Skeat left off, this thesis focuses on the three scribes and tries to describe their respective scribal behaviour, that is, their distinctive habits, their cooperation, and their characteristic faults. Among the questions dealt with in the study is the following: Is it possible to make a distinction between the scribes on the basis of the copying errors? The problem, of course, in asking this question is that we only have Sinaiticus and not the exemplar that was the source of the text of Sinaiticus. A tool has been developed by scholars such as E. C. Colwell and J. R. Royse, and has been further applied to the fragmentary papyri by Peter M. Head, which tries to deal with this problem. The method of singular readings claims that by concentrating on the unique readings in a manuscript, that is, readings that are only found in a single manuscript and not in any other, one studies the habits of the scribe of that manuscript. The scribe created readings (textual variants) during the process of copying which were not present in his exemplar. Whether he did this accidentally or intentionally is not relevant at this point. Of course, some scribecreated readings will appear also in other manuscripts and these will be falsely excluded by the method of singular readings. Others will be falsely included because the scribe found them in his exemplar and copied these readings faithfully. However, it is thought that, on average, these two categories of errors will compensate for one another and that by considering the singular readings, one approximates towards the readings the scribe introduced into the text. This method has been mostly applied to Biblical papyri and so far it has never been demonstrated that this method actually delivers what it promises, namely, that one is looking at the personal contributions of the scribe rather than at inherited features. 
Sinaiticus shows a few interesting features that help us test the method of singular readings and getting to know the scribal habits. Firstly, in the Old Testament part of the manuscript we find five leaves containing text from 1 Chronicles. This section ends with 1 Chronicles 19:17 and finishes within the 26th line of the fourth column of a leaf. The same line continues with text from 2 Esdras 9:9 and the following leaves complete this book. Two of the running titles placed above the section from Chronicles read $\varepsilon \sigma \delta \rho \alpha \varsigma \beta$ and it seems clear that the scribe was not aware that he was dealing with a large intrusion from 1 Chronicles into 2 Esdras. There is a note in Sinaiticus telling us that 'at the sign of the three crosses is the end of the seven leaves which are superfluous and not part of Esdras'. This note is in a later hand from the seventh or eight century and informs us that the original intruded text from 1 Chronicles contained two more leaves. These two leaves are now lost, together with most of the Old Testament before this point. Tischendorf had already suggested that it was likely that a gathering of leaves, a quire, was misplaced in the exemplar from which the scribe was copying and that neither he nor his colleagues noticed this. Indeed, we find corrections on the text by the scribes both before and after the transition from 1 Chronicles to 2 Esdras without any indication that something had gone fundamentally wrong. This unique situation provides us with an opportunity to learn something more about the copying errors which the scribes made. On the five extant leaves of 1 Chronicles, two of the scribes made 90 corrections in total. It is highly unlikely that they used any other manuscript for these corrections than the one that was used for the copying of the text in the first place. This means that every correction is a correction of a real copying error and that the correction is the true text of the exemplar. Using the corrections, we were able to create a catalogue of scribal errors. Interestingly, not all the 90 readings that were corrected are singular readings. Thirteen out of 90 readings also occur in other manuscripts and, consequently, would not have been detected using just the method of singular readings. These thirteen readings consist mainly of the addition and omission of small words such as articles, some orthographic variants, and harmonisations to the immediate context.

A second feature of Sinaiticus which proves helpful is found in the book of Psalms. This book is written by two scribes: the first twenty five and a half leaves by scribe $\mathrm{D}$, the remaining fifteen and a half 
leaves by scribe A. An interesting difference exists in the overall ratio of singular readings between the two scribes: scribe A has double the number of singular readings. The distribution of the singular readings over the various categories fluctuates, indicating that scribe A does not simply produce more singular readings, but that he tends do this in some categories more than in others.

Thirdly, in the New Testament, scribe D replaced on three occasions a pair of leaves (forming a single sheet) within text written by scribe A. Two of these replacement sheets were compared with the surrounding text. Both in Luke and the Pauline letters, the difference between the number of singular readings in scribe D's text and scribe A's text turns out to be dramatic, scribe D producing the far cleaner text. On the basis of these studies of singular readings, we could demonstrate that, in the case of Sinaiticus, the method of singular readings indeed delivers what it claims to, namely, that it identifies the habits of the individual scribe. However, again based on the situation in Sinaiticus, it will falsely exclude more readings than it will falsely include.

Besides the study of singular readings, also a number of other features of Sinaiticus are analysed. The pattern of itacistic changes is studied and quantified, revealing a characteristic pattern for each of the three scribes but a remarkable deviation of his normal pattern by the scribe responsible for Matthew. Also the common abbreviations for certain words such as 'God', 'Jesus', 'Spirit', and 'heaven', known as nomina sacra, are studied in the light of individual scribal usage. Each of the three scribes has different preferences for the precise form of the nomen sacrum, but also for the frequency of abbreviations (not every word is always abbreviated). Sinaiticus is also the earliest testimony to the Eusebian apparatus - a system of marginal numbers linking related passages in the gospels through a set of tables. Though the tables are not present in Sinaiticus, the position and form of the numbers can still be studied to learn more about the manuscript. All these individual studies not only help to increase our knowledge of the manuscript itself, but also serve to create a profile of the scribal behaviour of the individual copyists. 